\section{Service users' views of moving on from early intervention services for psychosis}

Lester et al's paper is timely. ${ }^{1}$ Many early intervention in psychosis (EIP) teams have been in action for over 3 years and are refining discharge pathways to primary care. This interface is not just with colleagues but now also with commissioners. While there is robust economic evidence for EIP, this perhaps sits outside the regular reading of most GPs. ${ }^{2}$ This interface needs active management and should not be relied on to grow organically. Every interaction with GPs should name the team and provide opportunity for shared learning, enhanced by the many leaflets covering this area. $^{3}$ There is a need to help GPs to understand what patients have been experiencing for the proceeding 3 years and not just to advise on subsequent management. In a world of ever changing services it is particularly important that they can be supported to navigate their way back in and EIP teams would tend to maintain responsibility for this, sometimes necessitating a brief period of reengagement to do so. This is added value from an economically justified team. GPs are often left with a client who is still on medication and are quite reasonably asking for how long they may continue, when medication can be safely stopped, and what the considerations and risks in doing so may be. There is a concern that vocational aspects, that are particularly valued by clients, may be among the hardest to access from primary care.

\section{Peter Carter,}

Consultant Psychiatrist, Waltham Forest EIP, North East London NHS Foundation Trust, 714 Forest Road, London, E17 3HP. E-mail: Peter.carteranelft.nhs.uk

\section{REFERENCES}

1. Lester H, Khan N, Jones P. Service users' views of moving on from early intervention services for psychosis: a longitudinal qualitative study in primary care. Br J Gen Pract 2012; DOI: 10.3399/bjgp12X630070.

2. McCrone P, Knapp M, Dhanasiri S. Economic impact of services for first-episode psychosis: a decision model approach. Early Interv Psychiatry 2009; 3(4): 266-273.

3. Iris. Early intervention psychosis iris network. www.iris-initiative.org.uk laccessed 8 May 2012).

DOI: 10.3399/bjgp12X648981

\section{COPD in primary care}

As GPs working for the London Respiratory Team, we were extremely pleased to see the high profile given to COPD in February's $B J G P^{1-4}$ since we believe that primary care, as part of an integrated pathway, has a major role both in earlier diagnosis and continued management of this condition. We would like to highlight two concepts from our workstreams: ${ }^{5}$ first that COPD is as important as lung cancer lor TB or other serious illness) and second to view high quality stopping smoking support as the treatment for COPD. We are keen to promote straightforward techniques such as very brief advice on smoking ${ }^{b}$ and simple case-finding techniques ${ }^{7}$ that can be used even in time-limited consultations to provide systematic and opportunistic earlier diagnosis of COPD and maximally effective intervention.

Opportunities to signpost patients in primary care range from receptionists noticing insidiously increasing breathlessness in patients they may have known for years, through to practice nurses who are ideally placed to offer case-finding spirometry to patients at risk of COPD. Increasing fragmentation of care within the NHS often means that the patient's registered GP may be the only healthcare professional in a position to spot recurrent chest infections, for instance, diagnosed out-of-hours or at walk-in centres, or to offer follow-up following an emergency department attendance. Earlier and accurate diagnosis in turn leads to proven interventions such as stopping smoking as a treatment and pulmonary rehabilitation. Per quality-adjusted life year, these treatments are highly cost effective at around $€ 2092$ and $€ 2000-8000$ per quality adjusted life year respectively. ${ }^{8-9}$

Within London, we're making the case for change in respiratory services by advocating a value-based approach to COPD health care. Work is needed across the UK to get the best value from the respiratory programme spend. The coming months will be a key time for clinicians and commissioners to debate where there could be improvements within the existing respiratory budget by maximising the outcomes that people with COPD want through the use of therapies that have proven cost-effectiveness.

Noel Baxter,

GP, Southwark, LRT Co-lead and Stop Smoking as a Treatment for COPD Clinical Lead.

Christopher Cooper,

GP, Islington, LRT GP and Earlier

Diagnosis Clinical Lead.

E-mail: chris.cooperlagp-F83015.nhs.uk

\section{REFERENCES}

1. Broekhuizen B, Sachs APE, Verheij TJM. COPD in primary care: from episodic to continual management. Br J Gen Pract 2012; 62(595): 60-61.

2. Miravitlles $M$, Andreu I, Romero Y, et al. Difficulties in differential diagnosis of COPD and asthma in primary care. Br J Gen Pract 2012. DOI: 10.3399/bjgp12X625111.

3. Martin A, Badrick E, Mathur R, Hull S. Effect of ethnicity on the prevalence, severity, and management of COPD in general practice. $\mathrm{Br} J$ Gen Pract 2012; DOI: 10.3399/bjgp12X625120.

4. Tsiligianni JG, van der Molen T, Siafakas NM, Tzanakis NE. Air travel for patients with chronic obstructive pulmonary disease: a case report. $\mathrm{Br}$ J Gen Pract 2012; 62(595): 107-108.

5. The London Respiratory Team. Workstreams. NHS London. http://www.london.nhs.uk/whatwe-do/our-current-projects/london-respiratoryteam/workstreams (accessed 8 May 2012).

6. NHS Centre for Smoking Cessation \& Training. Very brief advice on smoking. London: NCSCT, 2012. http://www.ncsct.co.uk/vba laccessed 8 May 2012)

7. Price D, Crockett A, Arne M, et al. Spirometry in Primary Care case-identification, diagnosis and management of COPD. Prim Care Respir J 2009; 18(3): 216-223

8. Hoogendorn M, Feenstra TL, Hoogenveen TR, Rutten-van Mölken MP. Long-term effectiveness and cost-effectiveness of smoking cessation interventions in patients with COPD. Thorax 2010; 65(8): 711-718.

9. Griffiths TL, Phillips CJ, Davies S, et al. Costeffectiveness of an outpatient multidisciplinary pulmonary rehabilitation program. Thorax 2001; 56(10): 779-784. 
demonstrates that doctors' behaviour can be changed by the use of data on their prescribing activities. The only intervention between September and December was a presentation of September's results to the clinical staff. Whether this will be sustained or not will be the subject of another audit.

\section{John Peters,}

Littlepace Medical Centre, Dublin 15, Ireland. regarding the influence of patient payment on antibiotic prescribing in Irish general practice. The Republic of Ireland is one of three European countries in which antibiotic use in general practice is increasing. ${ }^{1}$ Eligibility for Ireland's primary care services is determined by a means test with General Medical Service (GMS) card holders having access to GP services and medications free of charge. The remainder are private patients who pay a fee to access GP services.

We retrospectively reviewed a 2-week period in September 2011 in a practice with predominantly children and young patients presenting with symptoms that indicated a probable RTI (as in the Bradley et al study). The results were presented to the practice GPs and nurse in October and then a second 2-week period in December 2011 was then reviewed. Our results are shown in the table below.

The representation of GMS and private patients in September and December was approximately equal. Our findings show that there were more RTI presentations in December with less antibiotic prescribing overall, fewer antibiotics were prescribed to private patients in December, and higher use of delayed antibiotic prescribing.

As stated in many articles including the Bradley study, there are many external nonclinical factors that influence GPs prescribing such as patient's expectations, time constraints, patient volume, and mode of renumeration. 1,2,3,4 Our brief audit

\section{Table. Comparison of consultations for September and December 2011}

Parameter measured September December \% RTI presentations of $\quad 22.7 \quad 35.8$ total consults $\begin{array}{lll}\% \text { antibiotics given for RTI } \quad 67.8 & 60.0\end{array}$ $\%$ delayed antibiotics $\quad 27.9 \quad 37.2$ given for RTI \begin{tabular}{lll} 
\% GMS did get antibiotics & 53.2 & 57.6 \\
\hline
\end{tabular} \% PP did get antibiotics $83.7 \quad 62.5$ GMS = public patients. $P P=$ private patients .

\section{Claire Young,}

Littlepace Medical Centre, Dublin 15, Ireland. E-mail: iclaireyounglayahoo.ca

\section{Tom O'Dowd,}

Public Health and Primary Care, School of Medicine, Trinity College Dublin, Ireland.

\section{REFERENCES}

1. Murphy M, Byrne S, Bradley CP. Influence of patient payment on antibiotic prescribing in Irish general practice: a cohort study. Br J Gen Pract 2011; DOI: 10.3399/bjgp11X593820

2. Little P, Dorward M, Warner G, et al. Importance of patient pressure and perceived pressure and perceived medical need for investigations, referral, and prescribing in primary care: nested observational study. BMJ 2004; 328(7437): 444.

3. Coenen S, Michiels B, Renard D, et al. Antibiotic prescribing for acute cough: the effect of perceived patient demand. Br J Gen Pract 2006; 56(524): 183-190.

4. Geneau R, Lehoux P, Pineault R, Lamarche P. Understanding the work of general practitioners: a social science perspective on the context of medical decision making in primary care. BMC Fam Pract 2008; 9: 12

DOI: 10.3399/bjgp12X649007

\section{Situating general}

\section{practice training in the general practice context}

While I understand and agree with the longterm aim of increasing training time in the GP setting for GP trainees, I am unable to agree with some of the conclusions drawn by Goldie and Morrison. ${ }^{1}$

First, the training received in hospitals by GP trainees does not occur in isolation from the general practice setting. Within our vocational training scheme for example, during the time that our trainees are in their hospital placements our main focus is on putting their experiences into the general practice context. Furthermore, in our local deanery, all trainees do 6 months in GP practices prior to their final ST3 year, and this means that members of each small group are grounded with the perspective of the world they are preparing to enter. The socialisation and cohesiveness of the STs within their small group of GP trainees seems much more important than the more transient bonds formed while on hospital placements.

Second, obstetrics aside, I am sure that there is benefit to be gained by training in many hospital jobs as it allows the building of more specialist knowledge in commonly encountered general practice problems, for instance in sexual health, ENT, or dermatology. This knowledge is subsequently disseminated through peer learning to other members of their vocational training scheme small group and to the practices they work in later.

Finally, quality assurance of hospital posts means that the hospital leads for all our jobs are visited on a rolling cycle. We discuss with our hospital colleagues how our trainees can make the most of their time in hospital training experiencing, for instance, following a patient through a primary to secondary to primary care journey, understanding what makes a good referral from the hospital point of view, and viewing the primary care interface from the secondary care perspective. Given that commissioning is likely to lead to a more focused examination of the grey area between what can be done in primary or secondary care, fully understanding the boundary from all sides is likely to put us in a much stronger position to be able to manage it to the profession's best advantage.

Leaving aside the economic and logistical arguments of how to base training fully in primary care, arranging service provision in hospitals, or longer training in general practice, I strongly support extended training for GP STs within a primary care setting. I would, however, anticipate that an extra training year in the GP setting after completion of MRGCP would alleviate many of the concerns raised.

Tom Pelly,

Training Programme Director, Bristol Vocational Training Scheme, Severn Deanery, Horfield Health Centre, Lockleaze Road, Bristol, BS7 9RR.

E-mail: tompellyadoctors.org.uk 